\title{
GeoTAB: Clima, recursos hídricos e bacias hidrográficas na região de atuação da Embrapa Tabuleiros Costeiros
}

GeoTAB: Climate, water resources and watersheds in the work region of the Embrapa Tabuleiros Costeiros

\author{
M. A. S. Cruz ${ }^{1 *}$; R. O. F. Rocha ${ }^{1}$; A. A. G.Silva ${ }^{1}$; J. R. A. Amorim ${ }^{1}$; R. Aragão \\ ${ }^{1}$ Embrapa Tabuleiros Costeiros, CEP:49032-280, Aracaju-SE, Brasil \\ ${ }^{2}$ Centro de Tecnologias e Recursos Naturais, Universidade Federal de Campina Grande, CEP: 58429-900, Campina \\ Grande-PB, Brasil
}

*marcusascruz@gmail.com

(Recebido em 19 de junho de 2017; aceito em 28 de setembro de 2017)

O Portal GeoTAB da Embrapa Tabuleiros Costeiros, por meio de suas bases ClimaTAB e HidroTAB, visa disponibilizar via web dados geoespaciais relacionados a clima, recursos hídricos e bacias hidrográficas em sua área de atuação, que é composta pelos Tabuleiros Costeiros e áreas adjacentes (TCNEB), fornecendo informações que podem ser de grande valia ao processo de gestão dos recursos hídricos. Neste estudo são apresentados alguns produtos resultantes de análises realizadas com dados dessas bases relacionados à variabilidade das precipitações médias anuais e mensais, características de relevo e bacias hidrográficas. As precipitações médias apresentam volumes com maior concentração entre março e julho e sobre a faixa litorânea leste dos TCNEB, variando de 1600 a $2100 \mathrm{~mm}$ por ano. Mais de $88 \%$ da área de estudo localizase em altimetria inferior a $100 \mathrm{~m}$. Relevo Plano a Suavemente ondulado predomina em 54\% da região. As bacias hidrográficas presentes na região apresentam média propensão a inundações, com coeficiente de forma médio da ordem de 1,77 e baixo coeficiente de variação.

Palavras-chave: base de dados geográficos, Embrapa, geoprocessamento

The GeoTAB Portal of Embrapa Tabuleiros Costeiros, through its ClimaTAB and HidroTAB bases, aims to provide geospatial data related to climate, water resources and hydrographic basins in its area of activity, which is composed by Coastal Trails and adjacent areas (TCNEB), providing information that can be of great value to the process of water resources management. In this study are presented some products resulting from analyzes carried out with data of these bases related to variability of annual and monthly average rainfall, relief and hydrographic basins characteristics. The mean rainfall presents volumes with the highest concentration between March and July and on the eastern littoral range of TCNEB, varying from 1600 to $2100 \mathrm{~mm}$ per year. More than $88 \%$ of the study area are in altimetry less than $100 \mathrm{~m}$. Relief Flat to Gently wavy predominates in 54\% of the region. The hydrographic basins present in the region present a medium propensity to floods, with an average coefficient of the order of 1.77 and low coefficient of variation.

Keywords: Geographic database, Embrapa, geoprocessing

\section{INTRODUÇÃO}

Os tabuleiros costeiros do Nordeste brasileiro, bem como regiões adjacentes a estes, como a baixada litorânea e o agreste, região denominada neste texto de TCNEB, vêm apresentando nas últimas décadas uma intensa transformação do ponto de vista de sua produção agrícola e agroindustrial [1]. Se por um lado a economia na região mostra-se em constante evolução, com a diversificação de culturas, apesar da predominância de manejos agrícolas convencionais com nível tecnológico ainda carente, verifica-se também que estas modificações têm provocado impactos significativos sobre os recursos naturais, contribuindo para o incremento dos processos de degradação ambiental. Os ecossistemas presentes nos biomas desta região apresentam altos níveis de vulnerabilidade, como no caso da Mata Atlântica, restrita hoje a 8,5\% de seus remanescentes florestais e da Caatinga, cuja extensão também atinge a faixa litorânea na porção norte da região Nordeste, também com poucos remanescentes e apenas $1 \%$ de seus habitats naturais protegidos [1].

A dinâmica de uso e cobertura da terra está diretamente relacionada à evolução histórica das atividades agrícolas na região dos TCNEB, com predomínio de pastagens e culturas diversas, 
especialmente da cana-de-açúcar, o que vem promovendo mudanças significativas na condição socioeconômica e ambiental da região. Na região litorânea a expansão demográfica dos centros urbanos vem ocupando áreas cada vez maiores, em substituição a áreas anteriormente agrícolas ou naturais, provocando impactos significativos sobre os recursos naturais e a biota costeiros. A atuação eficiente de um centro de pesquisas agropecuárias de caráter ecorregional pressupõe um conhecimento profundo da dinâmica das atividades que ocorrem em sua área de atuação e, principalmente, das interrelações destas atividades com os recursos naturais existentes. Apenas considerando os aspectos descritivos acima resumidamente citados, observa-se o elevado grau de complexidade das interações entre os processos econômicos, sociais e ambientais que ocorrem nesta região de estudo, que aliados à sua grande extensão territorial, constituem-se em fatores que dificultam a identificação de demandas e o desenvolvimento de ações efetivas de Pesquisa, Desenvolvimento e Inovação (PD\&I). Esta diversidade de demandas de pesquisa levou a Embrapa Tabuleiros Costeiros a estabelecer de forma clara o seu foco de atuação, de modo a buscar atender com consistência e intensidade esse arco de realidades [2].

$\mathrm{O}$ conhecimento organizado, em informações com referência espacial, que retratem o comportamento da agricultura ao longo do tempo e a sua relação com os recursos naturais é indispensável para o planejamento eficiente de ações de PD\&I em uma unidade de pesquisa ecorregional como a Embrapa Tabuleiros Costeiros. A construção de um sistema de gerenciamento de bancos de dados com referência espacial (SGBDE) constitui-se em mecanismo de grande utilidade visando o armazenamento, manipulação e acesso às informações produzidas em estudos de zoneamento e monitoramento. Ademais, há uma gama de linguagens, livres de licença, disponíveis para o desenvolvimento e execução destes sistemas, com alto grau de confiabilidade, rigidez e agilidade. A definição de um SGBDE com ênfase em recursos naturais e socioeconomia deve conjugar aspectos relativos à possibilidade de sobreposição e cruzamentos de camadas de informações que permitam a interpretação de situações existentes e cenarizadas de forma a auxiliar nos processos de tomada de decisão, seja para pesquisa ou gestão governamental [3].

No ano de 2015, a Embrapa Tabuleiros Costeiros iniciou a execução de um projeto intitulado "Organização e disponibilização da informação geoespacial sobre recursos naturais e aspectos socioeconômicos da área de atuação da Embrapa Tabuleiros Costeiros", denominado projeto GeoTAB, que visa dispor informações sobre recursos naturais: solo, água, clima e vegetação; bem como aspectos socioeconômicos de relevância para a agropecuária na sua região de atuação por meio de um sistema de informações geográficas de livre acesso. O projeto prevê a construção e disponibilização das diversas bases de dados organizadas por meio de um sistema de gerenciamento de banco de dados geográficos com interface para Web, chamado Portal GeoTAB. Compondo o portal GeoTAB encontram-se as bases de dados ClimaTAB e HidroTAB, que armazenam informações georreferenciadas sobre climatologia e recursos hídricos, bem como limites hidrográficos e redes de drenagem. Entende-se que a disponibilidade de tal ferramenta contribua de forma significativa para a detecção de alterações na região e para o acesso a informações que subsidiem a tomada de decisão, nas diversas esferas de governo de setores da sociedade, promovendo maior agilidade nas respostas das instituições frente aos riscos e oportunidades que surjam relacionadas à atividades agropecuárias.

Este trabalho busca apresentar parte do conteúdo atual destas bases de dados e fomentar a sua ampliação com vistas a contribuir para a disseminação da informação organizada como ferramenta importante à gestão dos recursos naturais.

\section{MATERIAL E MÉTODOS}

A região de estudo (Figura 1), denominada aqui de Tabuleiros Costeiros no Nordeste brasileiro (TCNEB), contempla também algumas áreas adjacentes, que representam a área total de atuação da Embrapa Tabuleiros Costeiros. Esta região está compreendida entre as coordenadas geográficas $2^{\circ} 47^{\prime} \mathrm{S}, 41^{\circ} 26^{\prime} \mathrm{W}$ e $18^{\circ} 21^{\prime} \mathrm{S}, 34^{\circ} 46^{\prime} \mathrm{W}$, abrangendo 570 municípios nos estados do Ceará, Rio Grande do Norte, Paraíba, Pernambuco, Alagoas, Sergipe e Bahia, com uma área total de aproximadamente 219,5 mil km² [2]. Abriga uma população total de 27,1 milhões de habitantes, com grande concentração nas regiões metropolitanas, com cerca de 22,7 milhões de pessoas [4]. 


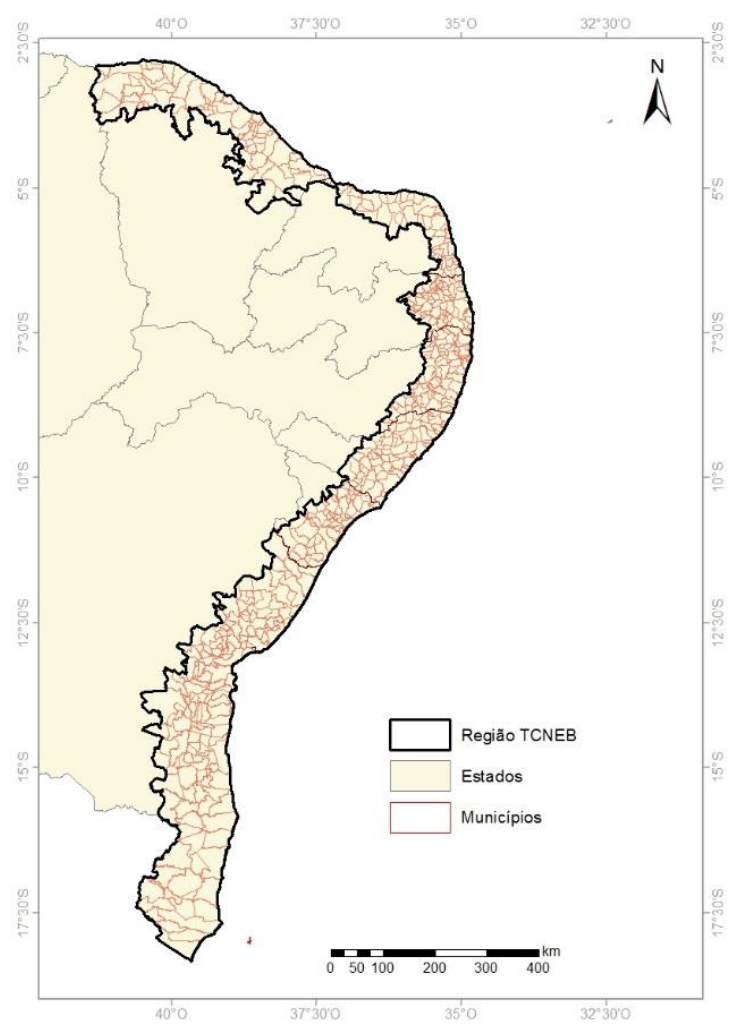

Figura 1: Localização da região de atuação da Embrapa Tabuleiros Costeiros do Nordeste (TCNEB).

Pela sua extensão, os TCNEB apresentam grande variabilidade de clima, solos, relevo e vegetação. As precipitações, considerando séries históricas de 1960 a 1990, variam de $400 \mathrm{~mm}$ (ao Norte em áreas do CE e RN) a 1900 mm (na costa de SE e BA) ao ano, com uma distribuição irregular. Nesta região observa-se a predominância do relevo plano a ondulado, com cotas altimétricas variando de 50 a $100 \mathrm{~m}$ e platôs sedimentares, ora com vales estreitos e encostas abruptas, ora abertos com encostas suaves e fundos com amplas várzeas [5]. Os solos nesta região apresentam-se profundos e com baixa fertilidade, pode-se destacar a ocorrência de Argissolos, Latossolos e Neossolos Quartzarênicos. Os solos apresentam de forma geral, carência de nutrientes, baixa capacidade de retenção de água, alta suscetibilidade à erosão, além da ocorrência de horizontes coesos, limitantes ao desenvolvimento das plantas devido a elevada resistência à penetração pelas raízes quando secos [6].

A distribuição das chuvas durante o ano mostra-se variável, com períodos de novembro a julho mais ao sul, mudando para abril a setembro na porção central e de janeiro a julho na porção setentrional. Esta variação associada às características dos solos e relevo são as principais causas da diversificação de culturas e atividades agrícolas na área de atuação da Embrapa Tabuleiros Costeiros.

Na porção sul da região de atuação da Embrapa Tabuleiros Costeiros, verifica-se a ocorrência de culturas como cacau, banana, mamão, café, guaraná, mandioca, feijão, milho, além de essências florestais e pecuária extensiva. Na porção central, verifica-se a presença de cana-de-açúcar, citros, coco, abacaxi, mandioca, feijão e milho, essências florestais, pecuária, carcinocultura e psicultura. Ao norte, observa-se a ocorrência das culturas caju, coco, maracujá, feijão, milho, mandioca, pecuária e carcinocultura [7].

As formações vegetais que se destacam na região dos TCNEB estão compreendidas no bioma Mata Atlântica (florestas, dunas e restingas) e os mangues, com ocorrências de Caatinga. Destacase que as coberturas vegetais nativas ainda presentes apresentam alto grau de alteração antrópica. A maior quantidade de remanescentes florestais do Nordeste encontra-se na porção sul do estado da Bahia [6]. 
A região de estudo tem importância estratégica para o Nordeste brasileiro, pois, apesar de ocupar apenas $14 \%$ da área dos sete estados, mais de $45 \%$ da população do Nordeste está localizada nos TCNEB [7]. A agricultura familiar mostra-se como ponto forte na região de estudo, uma vez que $77 \%$ dos estabelecimentos rurais são propriedades com área menor que 10 hectares [7].

A pecuária na região de atuação da Embrapa Tabuleiros Costeiros é representada principalmente pelas criações de bovinos de leite, carne, ovinos e caprinos. As pastagens apresentam ainda a predominância de manejos inadequados, com excesso de cargas e baixa reposição nutricional do solo, contribuindo para sua degradação em larga escala [7]. A carcinicultura também apresenta relevância na região litorânea do Nordeste, respondendo por $99 \%$ da produção nacional, estimada em 69,6 mil toneladas de camarão, com destaque para os estados do Ceará e Rio Grande do Norte. Quanto à psicultura, a região Nordeste detém a maior produção de pescado do país, com 454 mil toneladas, respondendo por $31,7 \%$ da produção nacional, com destaque para a Bahia e Rio Grande do Norte, ressalte-se que estes números não estão restritos à região litorânea.

Na citricultura, Bahia e Sergipe concentram $90 \%$ de toda área plantada da região Nordeste, com rendimentos da ordem de 15 ton/ha. Destaque para laranja, limão e tangerina. Apesar do destaque nacional, a produção de citros, principalmente em Sergipe, vem enfrentando dificuldades, com queda de produtividade atribuída à incidência de problemas fitossanitários, ao nível tecnológico empregado nos pomares, ao baixo investimento no setor e à estreita base genética das plantas [8, 9].

A cultura do coco na região Nordeste tem apresentado dificuldades de crescimento, apesar de encontrar na região condições de clima e solo mais favoráveis. A ocorrência de problemas fitossanitários e a queda prematura de frutos jovens têm contribuído para a diminuição da produtividade, com aumento dos custos de produção [10]. A exploração do coco seco concentra-se na faixa litorânea da região Nordeste, com predomínio de pequenas propriedades $(<10 \mathrm{ha})$ e uma produtividade média de 30 frutos/planta/ano, baixa, influenciada por fatores como: a idade avançada das plantas, material genético de baixa qualidade, deficiência no manejo de pragas e doenças.

A cultura da cana-de-açúcar tem apresentado expansão significativa na região Nordeste do Brasil. Parte dessa produção encontra-se localizada nos TC do Nordeste. Os Estados de Alagoas, Pernambuco, Paraíba e Rio Grande do Norte concentram cerca de $90 \%$ da produção do Nordeste [7]. Diversificação na produção e sistemas de manejo de solo e de produção para ambientes irrigados e colheita de cana crua são desafios aos produtores locais. Um grande desafio associado a esta cultura está também no controle da emissão de gases de efeito estufa (GEE) resultantes das queimadas [11].

A organização da informação sobre os recursos hídricos e bacias hidrográficas nesta região está sendo realizada por meio do levantamento de dados secundários e produção de informações a partir das bases disponíveis. Assim, estão sendo consultadas as bases da Agência Nacional de Águas (ANA) por meio do portal HidroWeb, Serviço Geológico do Brasil por meio do portal GeoBank, Instituto Brasileiro de Geografia e Estatística, Embrapa, além de buscas em bases estaduais, municipais e outras internacionais. Estão sendo levantados para a região os seguintes dados: Modelo Digital de Elevação (MDE) SRTM USGS com resolução espacial de $30 \mathrm{~m}$, localização e dados de estações de monitoramento hidroclimatológico, limites de bacias em diferentes escalas, redes de drenagem, localização e dados de estações de monitoramento de qualidade da água superficial e localização e dados de poços profundos.

A definição das bacias hidrográficas presentes nos TCNEB foi realizada a partir das informações em formato shapefile disponibilizadas no site da Agência Nacional de Águas (ANA), na forma de Otto bacias codificadas [12] e do modelo digital de elevação. Para a obtenção das bacias de influência na área da TCNEB, foi utilizado o software ArcGIS. Procedeu-se com o recorte da rede hidrográfica com base na delimitação das regiões nordeste e sudeste e, em seguida, a conversão do arquivo vetorial em um raster, utilizando a ferramenta raster calculator, que gerou um arquivo matricial com valores iguais a 1 para as feições lineares e zero para as áreas sem informação ou valor. Após a rasterização, o arquivo foi submetido às ferramentas de hidrologia Flow Direction, para determinar a direção de fluxo, e Stream Order, que utiliza o método de Strahler que atribui uma estrutura hierárquica de acordo com a junção dos canais dos afluentes até a foz dos rios 
principais. Foram obtidas área, perímetro e coeficiente de compacidade ou de forma das bacias hidrográficas.

Todas as informações estão sendo padronizadas em termos de referencial geográfico (SIRGAS 2000) e compiladas em sistema de banco de dados geográfico (SGDB) de formato shapefile/geotif, compatível com a maioria dos sistemas de informação geográfica (SIG). Mapas temáticos estão sendo elaborados utilizando técnicas de geoprocessamento, interpolação (inverso do quadrado da distância-IQD e krigagem) e calculadora raster, por meio dos softwares QGIS, R e ArcGis.

\section{RESULTADOS E DISCUSSÃO}

Neste estudo estão sendo apresentados alguns produtos já resultado de análises realizadas a partir dos dados levantados. Os dados de precipitação diária, utilizados neste estudo, foram obtidos a partir do portal Hidroweb da Agência Nacional de Águas [12]. Assim foram obtidos 760 postos na região de estudo. Em seguida, elaborou-se uma rotina em R [13] para realizar a seleção, considerando-se apenas os postos que dispunham de séries com mais de 30 anos de dados, menos de $20 \%$ de falhas e período recente (até pelo menos dezembro de 2015). Esta rotina procedeu ainda ao preenchimento das falhas e à análise de consistência das séries, utilizando-se, como base comparativa, o produto Brazil Gridded Meteorological Data [14]. Então, após todo o processamento, foram selecionados 158 postos pluviométricos com séries históricas diárias completas para o período de 1985 a 2015. Para efeito de facilidade de análise, os TCNEB foram divididos em quatro regiões segundo o comportamento das precipitações:

- Região 1: da divisa entre os estados da Bahia e Espírito Santo até a cidade de Valença-BA. Apresenta a maior precipitação média anual, variando em torno de $1.300 \mathrm{~mm}$ a $2.300 \mathrm{~mm}$, com período de chuvas concentrado entre novembro e julho.

- Região 2: Estende-se da cidade de Valença-BA até o rio São Francisco, na divisa dos estados de Sergipe e Alagoas. Apresenta precipitação média anual variando de 1.050 a 1.850 mm, nos meses de março a setembro.

- Região 3: Parte da divisa entre os estados de Sergipe e Alagoas e vai até a cidade de Touros no Rio Grande do Norte. A precipitação média anual, pode variar desde 1.200 até $2.300 \mathrm{~mm}$ com período chuvoso ocorrendo entre os meses de fevereiro e setembro.

- Região 4: Estende-se da cidade de Touros-RN até a divisa dos Estados do Ceará e Piauí. Esta região apresenta baixa precipitação média anual, variando entre 400 e $1.600 \mathrm{~mm}$ por ano, concentrada nos meses de janeiro a julho.

A maioria dos postos levantados está situada na Região 4 (93), seguida pela Região 1 (29), Região 2 (20) e Região 3 (16). Esses postos estão apresentados por região na Figura 2. 


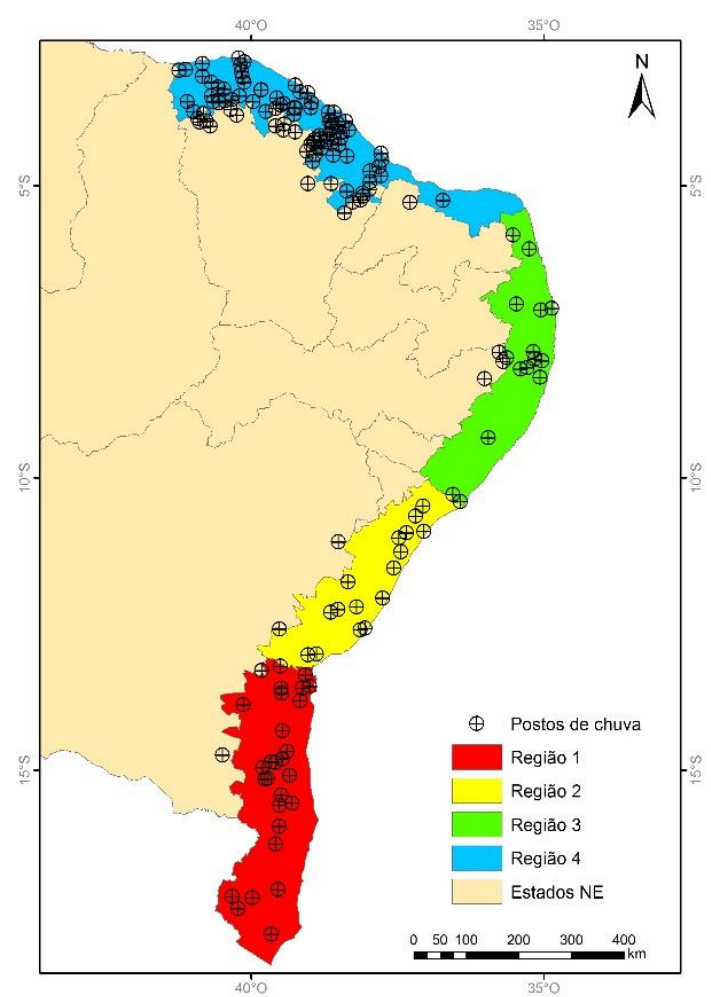

Figura 2: Localização dos postos pluviométricos nas quatro sub-regiões da área de estudo

A precipitação média anual ao longo de toda a região dos TCNEB, gerada a partir dos dados das estações por meio de interpolação via IQD com apoio do produto Brazil Gridded Meteorological Data [14], pode ser vista na Figura 3. Observa-se maiores alturas anuais de precipitação na faixa litorânea dos estados da BA, SE, AL, PE e PB, com valores da ordem de 1.600 a 2.300 mm, com redução significativa no $\mathrm{RN}$, atingindo cerca de $400 \mathrm{~mm}$, onde a região Semiárida estende-se praticamente até o litoral, e com um leve crescimento novamente para o estado de CE. Em toda a região dos TCNEB há redução dos volumes precipitados ao avançar no sentido do interior dos estados.

A Figura 4 mostra a variação mensal da precipitação em toda a região de estudo. Percebe-se que no mês de janeiro há ocorrência de chuvas no extremo oeste do estado do CE e no sul da BA, totalizando cerca de $120 \mathrm{~mm}$ em média. Em fevereiro e março os maiores volumes de chuvas concentram-se no estado do CE, atingindo acima de $250 \mathrm{~mm}$. Em abril as precipitações permanecem sobre o $\mathrm{CE}$, mas iniciam volumes consideráveis na costa do $\mathrm{NE}$, incluindo uma faixa do $\mathrm{RN}$ ao norte da BA, com cerca de $150 \mathrm{~mm}$ em média. De maio a julho as chuvas se intensificam nesta faixa litorânea (superiores a $250 \mathrm{~mm}$ ). De agosto a setembro há uma redução nas alturas precipitadas nesta faixa, indo de 80 a $140 \mathrm{~mm}$ em média. Em outubro verifica-se um aumento nas chuvas no sul da BA (acima de $100 \mathrm{~mm}$ ), com intensificação em novembro e dezembro (de 150 a $190 \mathrm{~mm}$ ), tendo as demais regiões em estiagem. 
M.A.S. Cruz et al., Scientia Plena 13, 109914 (2017)

7

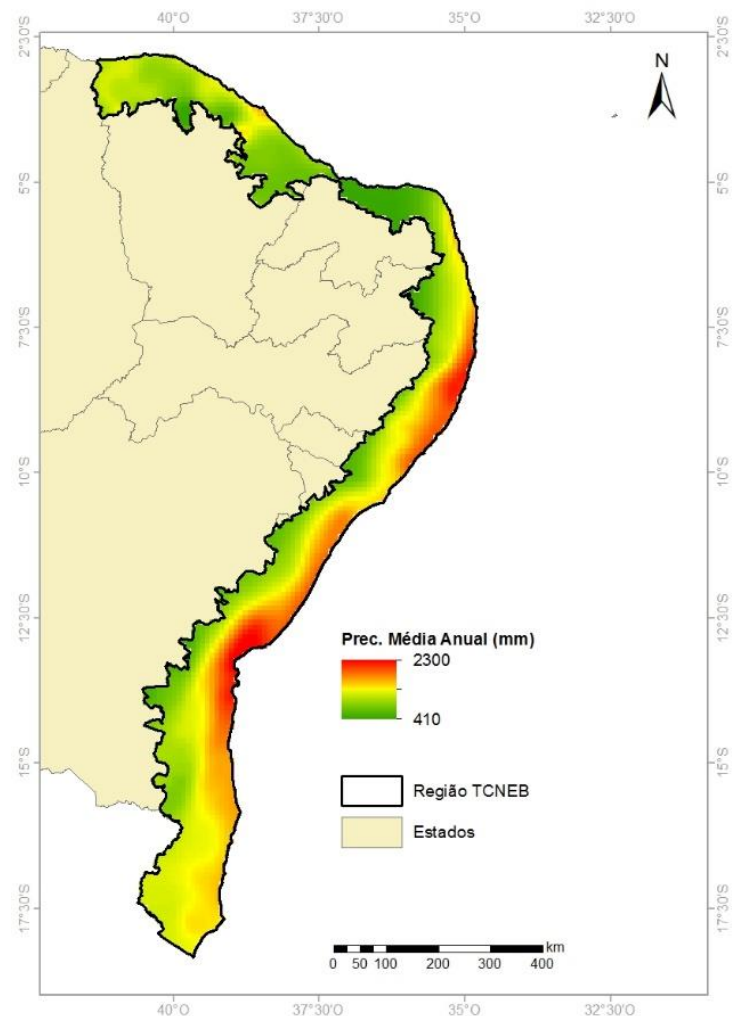

Figura 3: Precipitações médias anuais $(\mathrm{mm})$ na região de estudo dos TCNEB

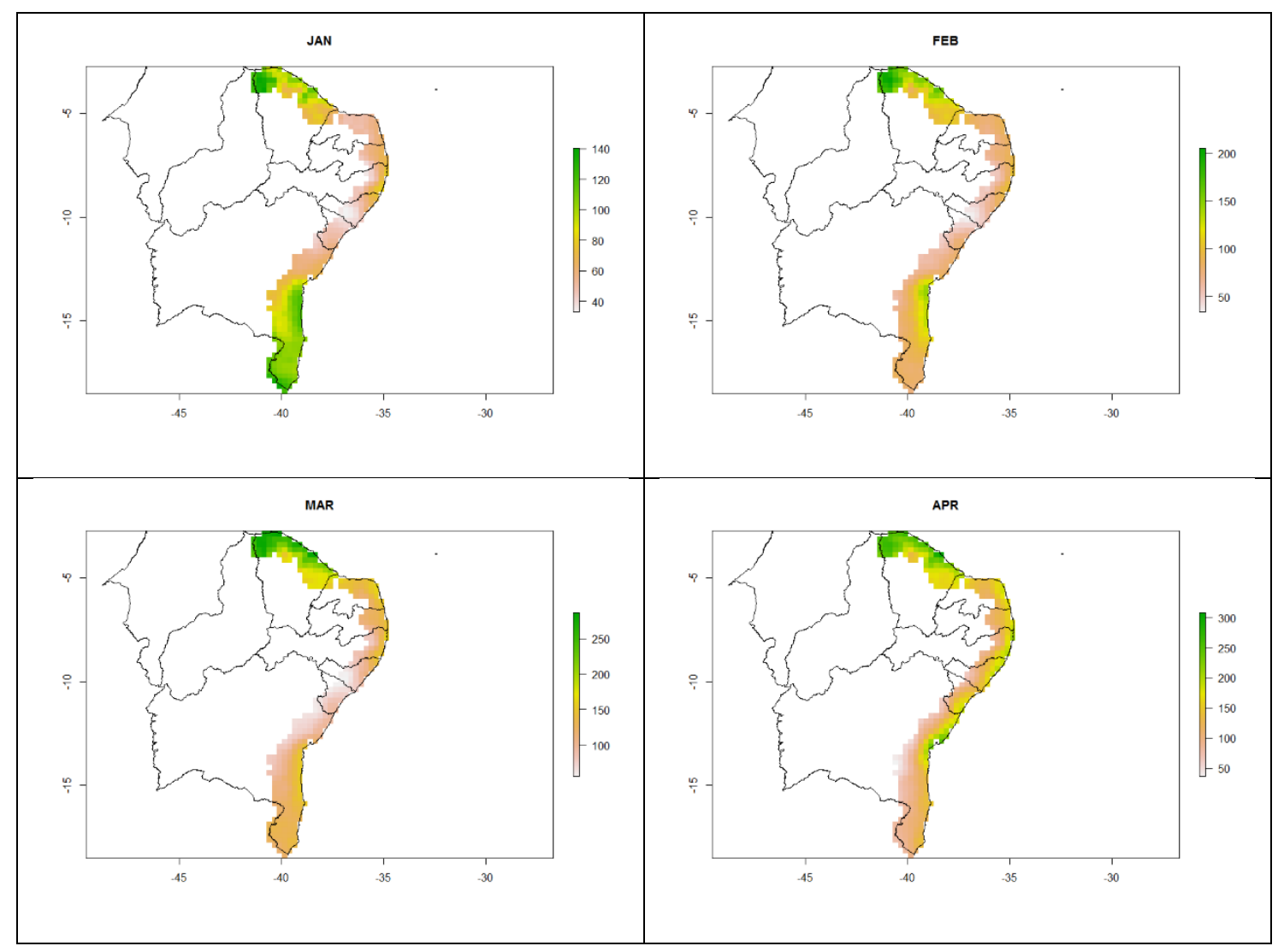




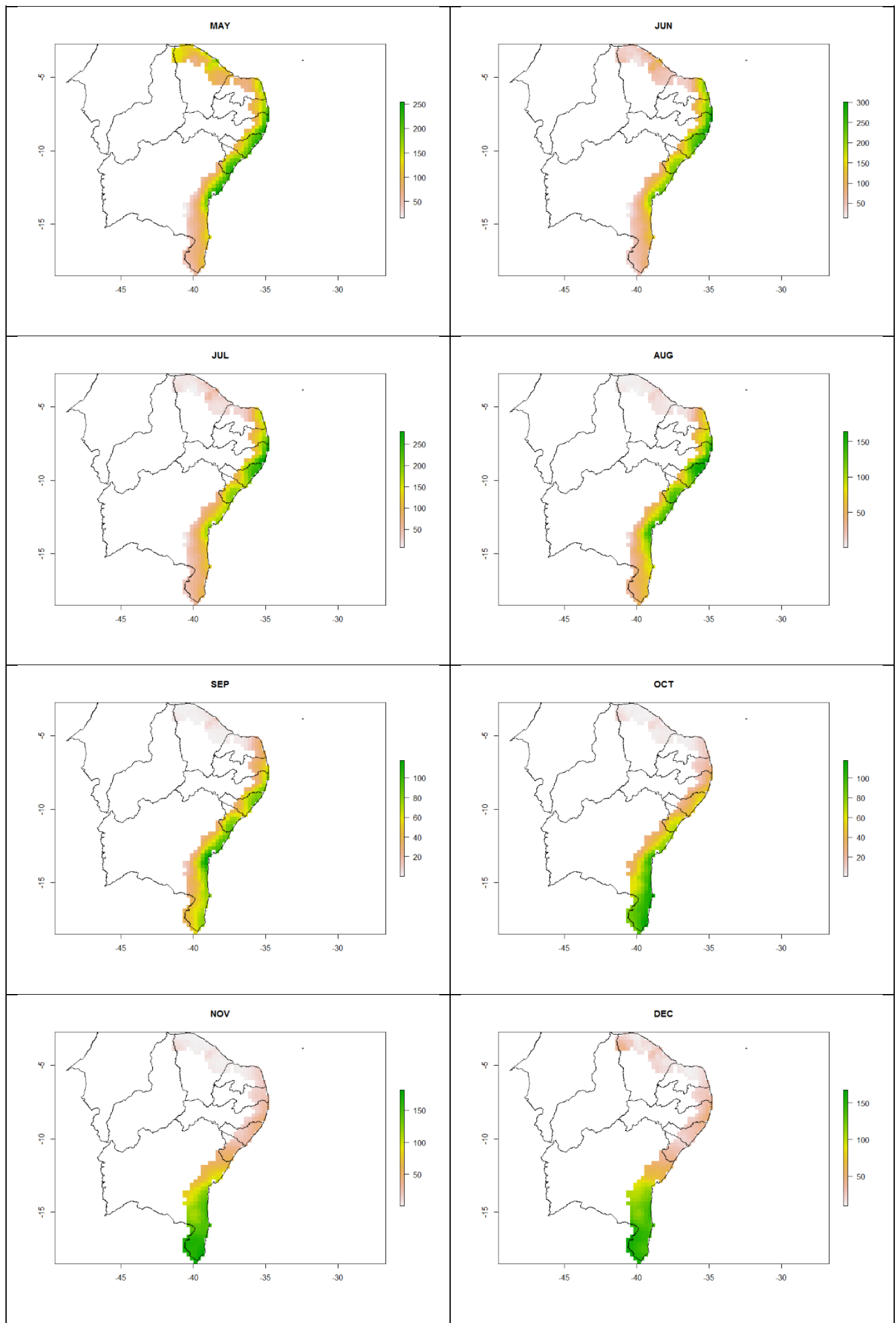

Figura 4: Precipitações médias mensais $(\mathrm{mm})$ na região de estudo dos TCNEB

Com relação ao relevo, observa-se na Figura 5, que em torno de $88 \%$ das áreas na região do TCNEB estão situadas em cota altimétrica inferior a $100 \mathrm{~m}$, e que as manchas de maiores altitudes se localizam no centro sul do estado da BA, em PE e PB e no estado do CE já na divisa com o 
estado do Piauí. Na Figura 5 pode ser observada ainda a classificação das áreas no TCNEB com relação à declividade do relevo. Verifica-se que há uma predominância de áreas classificadas como Planas (20\% da área total) a Suavemente ondulada (34\%). As áreas ditas Onduladas respondem por $27 \%$ do relevo dos TCNEB, com $17 \%$ classificadas como Fortemente onduladas e cerca de $2 \%$ como Montanhosas e Escarpadas. A maior parcela percentual das áreas planas fica localizadas nos estados do CE e RN.

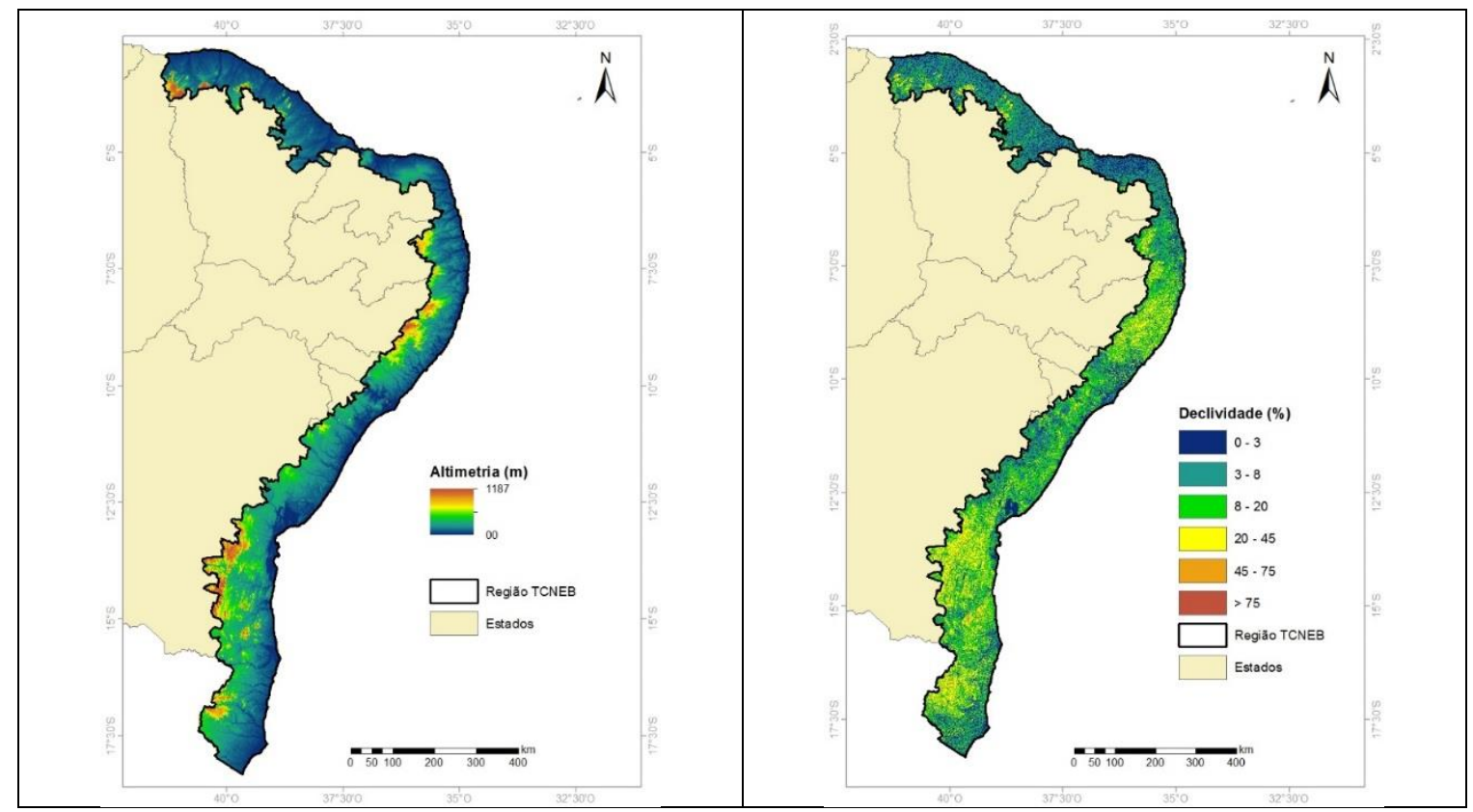

Figura 5: Variação altimétrica do relevo e classes de declividades médias do terreno na região dos TCNEB

A determinação das bacias hidrográficas existentes na região de estudo, foi efetuada por meio da seleção por atributos e por localização, destacando as Ottobacias de nível 5 que interceptam apenas os cursos de drenagem com níveis superiores a $3 \mathrm{em}$ um buffer de $150 \mathrm{~m}$ da área do TCNEB. Por fim, as bacias selecionadas foram reorganizadas de acordo com as Ottobacias nível 4. Foram obtidas 110 bacias hidrográficas, conforme características apresentadas na Tabela 1. Observa-se uma grande variabilidade nas áreas das bacias selecionadas, com valor médio de $2815,28 \mathrm{~km}^{2} \mathrm{e}$ coeficiente de variação acima da unidade. Observa-se que $25 \%$ das áreas das bacias encontram-se abaixo de $576,35 \mathrm{~km}^{2}$, sendo que grande parte destas estão localizadas mais próximas ao litoral. Com relação ao perímetro, a variabilidade mostrou-se bem inferior a demonstrada pela área, com valor médio de $289,65 \mathrm{~km}$ e coeficiente de variação de 0,61 . Os valores de média e mediana do perímetro foram bem mais próximos em comparação à área, indicando que esta variável pode apresentar comportamento gaussiano, diferentemente da área que deve mostrar elevada assimetria. $\mathrm{O}$ coeficiente de forma permite avaliar a tendência das bacias a grandes vazões de pico por proximidade à forma de um círculo $(\mathrm{Kc}=1)$. Assim, observa-se que o valor médio das bacias no TCNEB foi 1,77, muito próximo da mediana, indicando bacias com médio potencial de enchentes, observação reforçada pelo valor do quartil $25 \%(1,56)$ e pelo baixo coeficiente de variação $(0,18)$. 
Tabela 1: Estatística descritiva da área, perímetro e coeficiente de forma nas bacias hidrográficas na região dos TCNEB

\begin{tabular}{lrrr}
\hline Parâmetro & Área $\left.\mathbf{( k m}^{\mathbf{2}}\right)$ & Perímetro $\mathbf{( k m )}$ & Kc \\
\hline média & 2815,28 & 289,65 & 1,77 \\
mediana & 1805,01 & 263,85 & 1,78 \\
mínimo & 4,97 & 11,20 & 1,22 \\
quartil 25\% & 576,35 & 154,29 & 1,56 \\
quartil 75\% & 4414,01 & 408,55 & 1,97 \\
máximo & 16019,00 & 892,21 & 2,72 \\
desvio padrão & 2952,26 & 177,35 & 0,31 \\
coef. variação & 1,05 & 0,61 & 0,18 \\
\hline
\end{tabular}

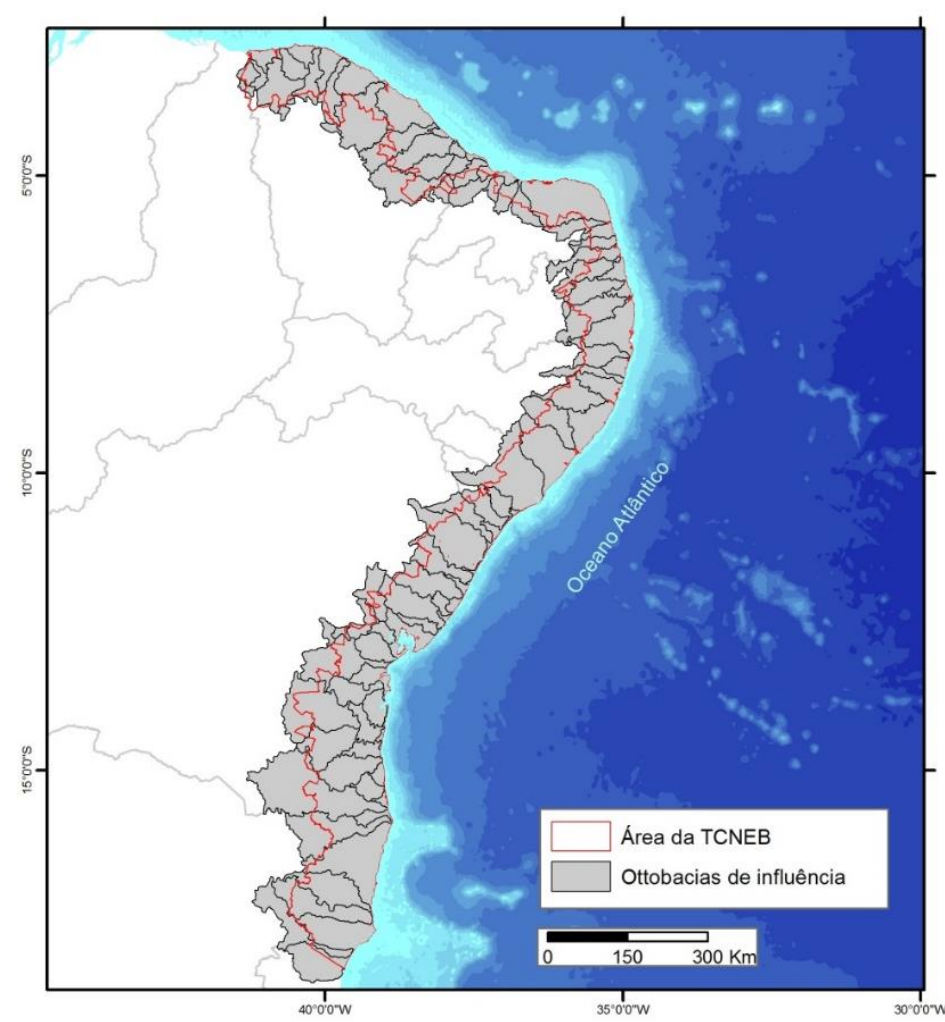

Figura 6: Bacias hidrográficas obtidas para a região dos TCNEB

\section{CONCLUSÃo}

Os dados levantados, organizados e trabalhados nas bases ClimaTAB e HidroTAB fornecem informações importantes ao processo de gestão hídrica nas bacias hidrográficas da região dos Tabuleiros Costeiros do Nordeste brasileiro. As precipitações médias anuais concentram suas maiores alturas na faixa litorânea do TCNEB, com valores de 1600 a 2100 mm. Há uma variação espacial em termos mensais na distribuição das precipitações na região de estudo, no entanto a maior parte das chuvas concentra-se entre os meses de março e julho. Mais de $88 \%$ da área dos TCNEB estão situadas abaixo da cota altimétrica $100 \mathrm{~m}$. A maior parte das áreas (54\%) que compõem a região apresenta relevo classificado como plano ou suavemente ondulado. As bacias hidrográficas presentes na região apresentam média propensão a inundações, com coeficiente de forma médio da ordem de 1,77 e baixo coeficiente de variação. 


\section{REFERÊNCIAS BIBLIOGRÁFICAS}

1. EMBRAPA. IV Plano Diretor da Embrapa Tabuleiros Costeiros 2008-2011. Embrapa Tabuleiros Costeiros, Aracaju. 2008. 40 p.

2. EMBRAPA. Relatório final dos trabalhos executados pela Comissão da O.S. No 09/2014 - Delimitação da área de atuação da Embrapa Tabuleiros Costeiros. Embrapa Tabuleiros Costeiros. 2014. 61 p. Disponível em: http://ainfo.cnptia.embrapa.br/digital/bitstream/item/142690/1/Doc-194.pdf. Acesso em: 02 jun. 2017.

3. Schaly KW. Ferramenta para criação de banco de dados geográficos a partir de diagramas OMT-G. 2009. Disponível em: www.lbd.dcc.ufmg.br/colecoes/erbd/2014/0013.pdf. Acesso em: 14 jul. 2014.

4. IBGE. Perfil dos Municípios brasileiros. Instituto Brasileiro de Geografia e Estatística. 2012. Disponível em: Acesso em: 03 abr. 2015.

5. Pereira VHC, Cestaro LA. A unidade geoambiental Tabuleiro Costeiro e o planejamento municipal: o caso de Senador Gorgino Avelino/RN. Rev Geonorte. 2012;3(4):390-401.

6. EMBRAPA. Zoneamento agroecológico do Nordeste do Brasil: Diagnóstico e Prognóstico. Embrapa Solos Recife. Embrapa Semiárido. CD-ROM. Documento n. 14. 2000. Disponível em: http://www.uep.cnps.embrapa.br/zoneamentos_zane.php. Acesso em 02 abr. 2015.

7. IBGE. Censo agropecuário. Instituto Brasileiro de Geografia e Estatística. 2006. Disponível em: http://www.ibge.gov.br/home/estatistica/economia/agropecuaria/censoagro/. Acesso em: 03 abr. 2015.

8. Souza LD, Sobrinho APC, Ribeiro LS, Souza LS, Ledo CAS. Avaliação de plantas cítricas, em diferentes profundidades de plantio, em latossolo amarelo dos Tabuleiros Costeiros. Rev Bras Frutic. 2004;26(2):241244.

9. Martins CR, Teodoro AV, Carvalho HWL. Citricultura no Estado de Sergipe. Artigo na mídia. Embrapa Tabuleiros Costeiros. Disponível em: https://www.embrapa.br/busca-de-noticias/-/noticia/2414294/artigo--citricultura-no-estado-de-sergipe. Acesso em 01 abr. 2015.

10. Jesus Júnior LA, Tommasi AC, Oliveira Júnior AM, Russo SL. Análise da produção de coco no estado de Sergipe frente ao crescimento da cultura no Nordeste e no Brasil. Rev GEINTEC. 2013;3(5):400-408.

11. EMBRAPA. Árvore do conhecimento: Cana-de-açúcar. Embrapa. 2008. Disponível em: http://www.agencia.cnptia.embrapa.br/gestor/cana-de-acucar/Abertura.html. Acesso em: 02 abr. 2015.

12. ANA. Sistemas de Informações Hidrológicas - HIDROWEB. Agência Nacional de Águas. 2017. Disponível em: http://www.hidroweb.ana.gov.br/. Acesso em: 03 abr. 2017.

13. R Core Team. R: A Language and Environment for Statistical Computing. Version 3.2.2. R Foundation for Statistical Computing. Vienna, Austria. Disponível em: < https://www.R-project.org>. Acesso em: mar. 2017.

14. Xavier AC, Kingb CW, Scanlonc BR. Daily gridded meteorological variables in Brazil (1980-2013). Int J Climatol. 2016 Mai;36(6):2644-2659, doi:10.1002/joc.4518. 